has rendered the instrument much more simple and less costly. Its value in surgical diagnosis has been proved by many surgeons in England, and Meyer of New York in 1889 wrote: "There is no doubt in my opinion (and no surgeon doubts it any more to-day) that cystoscopy has a great future. Of course, we have yet to learn in many respects to recognise the disease in the picture, and may often be mistaken in explaining what we see-just as may occur to laryngologists, and very experienced ones, with diseases of the larynx." This instrument is of especial use in the diagnosis of symptomless bæmaturia. The orifices of the ureters can be examined, and if blood is of renal origin it may be seen issuing from the ureter or ureters. Papillomatous growths, encysted calculus, hæmorrhagic cystitis, and en'arged prostate can be detected-in fact, it is a most important aid to the diagnosis of obscure disease of the bladder. Dr. Nitze has also introduced another ingenious instrument, the photocystoscope, by means of which photographs can now be taken of the interior of the living bladder.

Basteriology is a rery important aid to diagnosis, since so many diseases are due to definite specific micro-organisms which are recognised by their spe ial form and reaction to stains and manner of growth in culture media. Of course, this method of research cannot be carried out by the general practitioner, but at a small cost it can be done for us by the Clinical Research Association. The importance of this method applies in particular to the diagnosis of diphtheria and tuberculosis. So far as the diagnosis of diphtheria is concerned the modern physician does not feel comfortable or satisfied unless in at any rate all doubtful cases of sorethroat the opinion he gives is confirmed by bacteriolog;cal diagnosis. The diagnosis of phthisis has become much easier and can be made much earlier and with greater certainty since the discovery of the tubercle bacillus and its significant reaction to certain stains. In all suspicious cases of chronic lung disease an examination of the sputum should be made for these micro-organisms. Cholera is another disease in the diagnosis of sporadic cases of which a bacteriological examination for the comma bacillus is necessary.

Very great interest has been centred during the last few months in the so-called "new photography" the latest and one of the most startling and sensational scientific discoveries with which the name of Professor Roentgen is popularly associated. The chief medical interest in this discovery lies in the fact that bone is opaque and flesh trans parent, so that by means of these rays the skeleton of a living body can be photographed, as shown in the beautiful photographs reproduced in our medical journals ; and in this way the nature of deformities, obscure fractures, and dislocations can be accurately determined. It is almost impossible at present to realise the full importance of this discovery as an aid to medical and surgical diagnosis; but, judging from the great adrances alreary made, it seems possible that not only injuries of bone and foreign bodies in the tissues may be seen, but the diagnosis of such obscure conditions as renal and biliary calculi will be much facilitated. Another tribate to the immense importance of this discovery is the fact that one of these photographs has been accepted in a court of law as evidence of injury and substantial damages awarded in consequence. I quote from the report which is taken from the Sun of March 8th. 1896. "The Roentgen Rays in Court.-The Roentgen rays penetrated yesterday into the Assize Court at Nottingham, where Mr. Justice Hawkins was sitting at $N_{i s i}$ Prius. Miss Glarys Ffolliott, an actress, claimed damages from the Nottingham Theatre Company for injuries sustained through a faulty staircase in the defendants' theatre. During the hearing of the care a Londun medical practitioner $p$ oduced in evidence negatives of the plaintiff's left foot taken by Professor Ramsay by means of the new ${ }^{\prime} x$ ' rays. The negatives shower that the bones of the fout had been displaced. Mr. Justice Hawkins remarked that nowadays a man might be sent to an asylum bo having his hexld photographed. Verdict for the plaintiff, damages $£ 76$ 10:"

Gentlemen, I now bog leave to conclude. In doing so may I be allo ved to thank you for the honour you conferred on me by placing me in this chair, and may I also express my sincere and cor ial thanks to the honorary secretaries of this society, Dr. James Galloway and Dr. E. S. Tait, for the kindnfss and the able support I hare received frum them during the whole of my term of office?

\section{THE CAUSATION AND TREATMENT OF MAMMARY ABSCESS. ${ }^{1}$}

BY A. MARMADUKE SHEILD, M.B, B.C. CAMB., F.R.C.S. ENG.,

ASSISTANT SURGFOY AND LECTURER ON PRACTICAL SURGERY AT ST. GEORGE'S HOSPITAL.

IN these days of striking novelties in surgical matters there is always an inclination to commence with an apology when one writes a paper upon a medical or surgical malady of common occurrence, which is ordinarily met with in practice, and the diagnosis and treatment of which are supposed to be generally well known. Such a subject is suppuration within the mammary gland, and I have been induced to bring it forward because of its importance in all classes of practice, and because I feel sure that the operative treatment of mammary abscess as ordinarily conducted is by no means satisfactory in its results. The very commonness of the affection would serve as a sufficient plea for my bringing it before a society where men of all varieties of practice meet on common ground. There are many points regarding mam. mary suppuration of great interest. Not the least are some of the modern methods of treatment and the frequent dia. gnostic difficulties that from time to time arise. As regards the causation of these affections, though everyone connects them with suckling and lactation, yet instances occur in practice which are quite inexplicable on these grounds, and it is here that the special diagnostic difficulties arise which renders the subject of mammary abscess so immensely im. portant to surgeons. 'Taking first the common form of acute mammary abscess I need only state a few figures to show its close relation to lactation. The total number of cases of abscess of the breast admitted into St. George's Hospital between 1870 and 1895 was 200 . The right breast was more commonly affected. Both breasts were affected in 13 instances. There were 2 cases affecting males: 1 due to pyæmia and the other to a blow. Out of the 200 cases 169 were directly due to lactati $* n$ and referred to sore nipples in women of the child-bearing age. 31 were due to other causes; of these, 8 seemed directly attributable to a blow, 1 was due to necrosis of a rib and 22 were due to no certain cause; but of these in 5 instances the abscesses originated on the site of former abscesses, and there was in three a suspicion of the affection being tuberculous. In the 22 cases the patients were either young girls or women betrieen forty and sixty years of age. The youngest were eleven and fifteen and the oldest fifty-eight and sixty-seven years of age. In only 2 cases was the abscess submammary. In the majority of instances the pus was within the gland substance itself. In several of the older patients the abscess was thought to be a solid tumour, and the true nature was only discovered after exploration.

In like manner I have studied sixty cases of abscess of the mamma admitted into University College Hospital for six years, from 1884 to 1890 , selecting that period because then alone were full particulars given of the nature of the abscesses and the time they occurred after lactation. Of the 60 cases, 51 were associated with pregnancy or lactation in women of varying ages. The left breast slightly preponderates in order of frequency of attack. Of cases of chronic abscess there were eight occurring between the ages of thirty-five and fifty-one years. In one of these blows were mentioner as a like ly cause. Several of the chronic abscesses $W_{-i}$ e only differentiated from scirrbus by exploratory incision, being associated with ulceration of the nipple, and in one the nature of the contents seemed likely to show that the supposed abscess was really an arcient galactocele with in: pissated contents. One case of acute superticial abscess occurred in the male breast just beneath the areola, and no cause could be assigned for it. of 102 cases of abscess related by Dryant $^{2} 79$ occurred during lactation, two during pregnancy, and 21 in non-lactating, non. pregnant women. Birkett ${ }^{3}$ in exanining 149 cases of mammary suppuration noted that 132 of them occurred

1 A paper read before the Medical Society of London on April 27th, 2 Diseases of the Breast. Holmes's System of Surgery, rol, iii., p. 434. 
in suckling women. Among 72 cases published by Nunn 58 occurred in lactating women, 7 in pregnant women, and 7 in non-puerperal women. Of 230 cases collected by Jamain and Terrier ${ }^{*} 183$ were connected with the puerperal state, 47 occurred during pregnancy, and 34 were not connected with either condition. McClintock ${ }^{5}$ preserved notes of 83 cases of mammary abscess and found the preponderance on the left side. Of all the abscesses he had seen the vast majority made their appearance during the first six weeks of lactation. As regards the time after parturition that mammary abscess occurs I find the greatest variability. Some of the cases occur as early as the first, others not until the fourteenth month. Birkett ${ }^{B}$ found that in 116 cases half of them occurred as early as the first month after parturition, and a large proportion of these as early as the first week. In 50 of the St. George's Hospital cases collected by myself, where the time after parturition is noted, the majority occurred later than this, 38 cases occurring in the period between the second and the fourth month. Bryant ${ }^{\gamma}$ found that out of 102 cases 68 occurred in the first two months after pregnancy. It would seem very difficult if not impossible to strike an average regarding the exact month at which lactation abscess is the more common; but Nunn, Birkett, and Bryant are all agreed that this affection is most frequent in the early and late months of pregnancy. Birkett ${ }^{8}$ estimates that half of the cases are associated with defective or sore nipples. Personally, I believe the average is far higher than this, and I have never seen a case of acute mammary abscess in a young woman without being able to observe, by the aid of a lens, breaches of surface in the vicinity of the nipple by which organisms might readily enter the lymphatic channels. Through the courtesy of Dr. Griffiths and Dr. Grigg Thave been able to inspect the records of Queen Charlotte's Lying-in Hospital, and I was greatly struck at the remarkable infrequency of mammary abscess at that institution. Out of 2000 cases examined by myself, taken by selecting 200 at a time, out of different years in the practice of various physicians, to my surprise not a single case of mammary abscess was found. The medical officer was obviously on the alert to note such conditions, for cases of " milk-engorgement" with ibreatening inflammation were here and there noted. It is true that the majority of parturient women were early discharged from the hospital, say, in a fortnight or three weeks; but, on the other hand, it must be pointed out that most of the patients were primiparæe in whom tlue nipples are often badly developed, badly cared for, and frequently sore. The cause was not far to seek in the precautions taken by the physicians to ensure the cleanliness of the nipples and of the infant's mouth, and this brings me to enunciate the first important proposition of this paper, that in the vast majority of cases acute mammary abscess, whether during lactation or not, and in either sex is due to absorption by the lymphatics of organisms, which enter abrasions on the nipple or areola. The common organisms found on the skin can nowhere be more abundant than in the axilla or about the areola of the mamma-parts moist and protected and affording every opportunity for active increase and growth. Moreover, round the nipple is a fossa kept moist by the secretion of especial sebaceous glands, and in such a locality organisms most abound. The least breach of surface is inoculated as surely as though the surgeon had rubbed in the virus intentionally.

During lactation the vascularity of the breast and the rapidity and vigour of its lymphatic circulation render absorption very marked. The organ is engorged with blood and full of an animal thuid, affording an excellent medium for the prolification of organisms. All these considerations are sufficient to explain why the least breach of surface about the nipple of a lactating breast so readily leads to abscess. Modern investigitions into the true causes of suppuration exclude engorgements of the mamma as having anything to do with mammary ibscess except as a predisposing cause. In former days the milk was thought to be the cau:e of mammary and puerperal atfections. Thus, puerperal insanity was termed "manid lantea", and iliac phlebitis was commonly termed "milk-leg." These erronejus terms were first publicly denounced by Meigs, who applied the contemptuous epithet

4 Manuel de Pathologie et de Clinique Chirurgicales, tome iv.; Maladies du Sein, p. 686

( Holme p. 309-310. 7 'S System of Surgery, vol. iii., p. 435.
Diseases of the Breast, p. 25. 8 Op. cit. of "milkmen" to his professioual opponents. 'The oryauioms ound on the skin capable of originating suppuration are probably numerous and need not here be enumerated. Modern writers on dermatology, especially in Germany, have recognised the fact that many ot the suppurative affections of the skin associated with locil infective qualities, as boils, pustules, and impetiginous eczema, are due to the entrance of org inisms, especially staphylococci, by minute abrasicns or ly the mouths of the ducts of the sebaceous glands. ${ }^{9}$ Dr. Slater, bacteriologist to St. George's Hospital, has kindly examined for me the pus taken from acute mammary abscess. In all of the cases abundant staphylococci were found, principally the staphylococcus aureus. Jamain and Terrier are of the same opinion. "Abscess of the breast," write these authors, "is the result of infection." The most common agent is the staphylococcus, sometimes the streptococcus, and, according to Bumm, in exceptional instances the gonococcus. In accordance with the view that all cases of acute mammary abscess are due to the entrance of organisms from the neighbourhood of the nipple, I must view with doubt those cases of so-called acute idiopathic abscess that occur in the unimpregnated condition. Among the St. George's Hospital cases are found instances of acute abscess occurring in girls as early as the age of fifteen and eleven years, and no apparent cause was to be found. In neither of those cases was an examination made of the nipple and areola with a lens, and without such precaution an abrasion may be readily overlooked. I had an opportunity of observing an important case which bears out this view under the care of Mr. Pick in the wards of St. George's Hospital during the past year. A middle-aged, healthy-looking single woman had noticed for about a vear that the left nipple was occasionally "a little sore." A week before admission she had complained of acute pain in the left breast with some swelling. There was an apparent tumour the size of an orange in the left breast, hard but markedly tender, with a sense of elasticity towards its centre and a faint red blush on the skin. At the base of the nipple was a small abrasion covered by a scab. The appearances were very similar to scirrhous cancer. An exploratory incision evacuated creamy pus, which was examined by Dr. Slater and found to contain the staphylococcus aureus in abundance. The abrasion on the nipple might readily have been overlooked without close examination.

Although in the numerous instances where chaps and excoriation about the nipple beccme infected with organisms, the staphylococcus - especially the staphylococcus aureus-appears to be common, yet there is nothing to prevent organisms of a more virulent nature from entering the tissues. This will perhaps explain cases which the older writers used to term diffuse phiegmon of the breast, where the tissues became gangrenous and the patient rapidly sank. Such cases are certainly rare. I have never seen one, and they are scarcely mentioned by modern surgeons. Velpeau il notices the case of a healthy and poxerful young woman, who was neither pregnant nor recently confined, who was attacked with what was considered to be "erysipelas" near the left nipple. The swelıing increased with a rapidity similar to that observed in the scrotum, ejelids, or cellular tissue elsewhere. A large gangrenous patch formed over the external half of the gland and the patient rapidly sank. In such a case modern investigation would probably have discovered such organisms as streptococci and the bacillus septicus.

The cases, says Spiegelberg, in which abscess of the mamma is pirt of general septic infection must be very few. Rokitansky mentions the occurrence, and other cases are related by McClintock and one by Spiegelberg ${ }^{12}$ himself. McClintock's case of abscess due to general septic infection is referred to in his clinical memoir on diseases of women (page 325). "Only one example has fallen under my notice in which I felt satisfied the abscess of the breast was purely symptomatic. In this instance it succeeded to uterine pulebitis. An enormous swelling, attended with great pain and some discolunration of the skin, formed in the superior part of the right mamma extending upwards to near the clavicle. On dissection, an immense quantity of unhealthy purulent fiud was infiltrated throughout all

9 Malcolm Morris: Diseases of the Skin, p. 327.

10 Manuel de Patho'ogie et de Clinique Chirurgicales, tome iv. deuxtème fascicule, $\mathrm{p} \in 8 i$.

12 Text-book of Midwifery, vol. ii., p. 408. 
the structures of the part." The records of the Middlesex and University College Hospitals show us no examples of pyæmic abscess of the breast, and it is not mentioned by writers of repute. I have only been able to find one case of abscess of this nature in the records of St. George's Hospital in twenty-five years, though it is right to point out that in fatal cases of pyæmia a small abscess in the breast may readily have been overlooked. A feeble man was admitted into St. George's Hospital on July 30th, 1884. He was too ill to give an account of himself, but it was gathered from his wife that he had been ailing for about ten weeks with " aches and pains all over him." Five weeks before admission a painful swelling began to form in the left breast and right nipple. On admission a large abscess was opened in the left breast, and an incision over the right inner malleolus was made through brawny indurated tissue. This patient remained in the hospital for nearly seven months with all the symptoms of chronic pyæmia, abscesses being opened in the buttock, the calf of the leg, and the sterno-clavicular articulation. He finally recovered after a severe and protracted illness. The primary focus of infection was doubtful, but abscess undoubtedly first formed in the left mamma.

I have asserted that the vast majority of cases of acute mammary abscess are caused by the direct action of organisms which enter the lymphatic channels. There yet remains another possible method of infection which is of the highest interest and which possibly has not received the attention it deserves-i.e., the entrance of organisms along the milk ducts themselves. I have already referred to the fact now well known among dermatologists that organisms may enter the sebaceous glands of the skin and thus produce the phenomena of boils and pustules. Seing that the breast is only a highly differentiated sebaceous gland one suspects that the same might here occur. Nocard of Lyons produced tuberculous mammary abscess by injecting tuberculous virus into the milk ducts of a lactating goat. Boissard in a clinical lecture delivered in Paris in $1893^{13}$ speaks very positively of the invasion of the milk ducts by streptococci and staphylococci $\mathrm{He}$ terms the resulting suppurative affection galactophoritis. Chassaignac called the disease canalicular intra-inammary abscess Nyeth $^{31}$ relates the case of a woman aged torty-two years who was non-lactating and affected with bilateral mammary abscess which burrowed through and destroyed both breasts. He terms the case infection of the mammary gland through the nipple and galactophorous ducts. The destruction was so extensive that both breasts were ultimately amputated, which seems a very severe remedy. The branching nature of the abscesses along the milk ducts seems especially to impress the writers upon galactophoritis. It is always open to doubt in these cases that some breach of surface dues not really exist, and although the experiments of Nocard place it beyond doubt that infection by the ducts is possible it is certainly not common. For three years I have closely examined a number of cases of mammary inflammation and abscess without finding a single case where I could certainly attribute the abscess to infection through the milk ducts themselves. Moreover, in 1894 Professor Sherrington and myself performed two experiments at the Brown Institute which had a negative result. In a lactating cat and a lactating rabbit milk was squeezed from the mammary gland, and where the ducts were empty and ready for absorption pus was well rubbed into their orifices and allowed to dry there. In one case fresh pyæmic pus was used, in the other secretion from a tuberculous abscess. In neither of the cases did any reaction or alteration occur. I think these two experiments, which were carefully done, go some way to show that suppurative processes do not readily pass along the milk ducts of animals. What the effect of gonorrhœeal pus upon the milk ducts of the human subject may be it is, of course, impossible to prove by experiment; but judging by the way it affects the urethra one would imagine that purulent inflammation would readily result. The principal importance of purulent inflammation of the milk ducts are the serious results which may possibly occur to the infant. We bardly yet quite understand the extraordinary influences which the mother's milk may exercise on the infant for good or bad. We, indeed, are aware that certain drugs are excreted with the milk and that emotional disturbances and febrile attacks on the part of the mother have deranged the digestive system of the infant. The presence of pus in the milk wonld be likely to cause very serious consequences, and I recommend this investigation especially to those who are interested in the dietary and management of young infants. Dr. R. A. Gibbons ${ }^{15}$ relates a most interesting example of fatal and acute purpura hæmorrhagica in a child. 'The case is a very striking one, and one can hardly doubt on considering it that the condition was due to the pernicious effect of pus in the milk. The child had suffered from severe diarrbea and was progressing well upon asses' milk until suddenly he became extremely ill with severe epistaxis and all the familiar symptoms of hæmorrhagic purpura. He died after an attack of severe hæmatemesis. About six days previously to his death his mother noticed a thick sediment in the milk, and on inquiry being made the donkey which supplied the milk rvas found to be suffering from abscess of the udder. Dr. Gibbons states further to me: "I know of two cases in which mammary abscess was developed, and before the sup. puration was pronounced the infants were ill. One of these cases, a wet-nurse, I admitted under my own care at the hospital, and she had several abscesses of the mamma."

The influence of blows in causing abscess of the breast is well known. When suppuration occurs in the male breast it is usually due to this cause. Bryant ${ }^{16}$ found that of 12 cases 8 were aitributed to local pressure or injury, causing extravasation of blood. I have notes of 3 cases where abscess of the male breast followed a kick, a blow from the horn of a cow, and the pressure of a shoemaker's last. In these instances it seems quite plain that a communication is established between an area of tissue containing extrava. sated blood, the resistance of which is impaired, and the external parts through the torn or injured ducts, and hence organisms may enter and produce injurious effects. Abscess in the breast of infants has been frequently recorded and appears to be largely a preventable malady. The milky exudation which flows from the nipples of some infants is almost entirely due to disintegration of the central cells of the columnar epithelial masses of which the primary gland is formed. When ignorant nurses in these cases pull or rub the nipples a breach of surface is effected by the rupture of a milk duct or abrasion of the integument of the nipple, and, organisms entering, an abscess is the result. In the well-conducted large "lying-in" hospitals of this city abscess of the breast in infants is practically unknown, yet the swelling and hyperæmia associated with secretion of spurious milk are not uncommon and of $t \in \mathbf{n}$ lead to feelings of alarm in the mind of the medical attendant. A case of mammary abscess in an infant three weeks old is related by Dr. Stephen of Lettercairn. ${ }^{17}$ It is said to have been caused by "retention of milk." The child, a female was sixteen days old when the right breast inflamed, pointed, and was opened, when about an ounce of thick greenish pus escaped. On examination a milky secretion was found issuing from the left breast, which was examined with the microscope and found to resemble the maternal milk except that the latter contained more corpuscles. A case of double mammary abscess in a male infant is related by Dr. Wilks of Ryde.18

Attention being drawn to the subject, a number of cases of abscess in infants are recorded by various practitioners. ${ }^{19}$ Most observers refer the occurrence of the abscess to the practice prevalent among jgnorant nurses of pulling and rubbing the nipples. Dr. Robert Barnes ${ }^{20}$ backs up this assertion and states that when he was house surgeon to a lying-in hospital he encountered several cases of abscess in the breasts of infants due to the manipulations of nurses. Numerous other instances may be found in surgical literature where experienced practitioners attribute cases of abscess in infants to this practice.

In cases of swelling and engorgements in the breasts of infants were the attendant content to keep the parts about the nipple scrupulously clean with a very dilute mercurial wash and to apply graduated pressure with cotton-wool and bandage the phenomena of abscess would probably never occur. Suppuration in connexion with new growths in any part of the body is extremely rare, and the same is true of new growths of the breast. Abscesses may, however, be found in the neighbourhood of ulcerating cancer, and the same phenomenon is sometimes observed in other parts; thus

15 Medical Times, Jan. 3rd, 1885. 16 Diseases of the Breast, p. 53 . is Med. Jour., July $25 \mathrm{th}$

t9 Ibld.. Aug. 8th, 1874. 
we find abscess of the neck with ulcerating epithelioma and abdominal abscess with ulcerating carcinoma of the intestine. In very exceptional cases the cysts of sarcoma or adenoma may contain pus. Should they be artificially inflamed or inoculated with septic material, as by the introduction of a dirty trocar, suppuration is, of course, not uncommon. In the days when caustics were employed to remove cancers of the mamma, surrounding abscess and cellular inflammation were often enough exemplified. In the year 1867 a patient was treated in St. Grorge's Hospital for scirrhus of the left breast with the chloride of zinc paste inserted in the form of arrows into the diseased mass. The whole breast sloughed out, but severe rigors and ferer ensued, and a large abscess formed in the other breast. The patient died apparently from pyrmia. A good instance of abscess of the breast in association with scirrhus is the following. A woman aged seventy-six years was in St. George's Hospital in 1883 with a hard scirrhous cancer growing in the left breast and which had existed for two years. Lately the tumour had ulcerated, the nipple was retracted, and the skin adherent. There was a large abscess stretching from the nipple to the axilla. The abscess was opened and much foul pus evacuated. The tumour and pectoral muscle to which it was adherent were removed. The patient recovered favourably. A single woman aged thirty-three years was in St. George's Hospital in 1889 suffering from a tumour of the left breast. She stated that this harl existed for six weeks, but the history was very doubtful. Her mother had died from uterine cancer. The patient had always suffered from a painful and retracted nipple. On examination there was a large, round, tender, movable swelling in the upper part of the left breast and theskin was non-adherent. There were some enlarged axillary glands. At consultation exploratory incision was decided on. This being petformed, pus was discovered and the sac of the suppored abicess with the surrounding breast tissue disseated out. It was later discovered that papillary growths were present on the walls of the sac. Thus the case was really one of suppurating cyst. Such instances are exceedingly rare. In the past year $I$ saw my colleague, MI. Bennett, operate upon a large cystic sarcoma. One of the cysts discharged pus abundantly and there was practichlly a sinus communicating with a large abscess cavity. This had resulted from a puncture with a lancet made outside the hospital into one of the main eysts in connexion with the growth, allo ving the cystic cavities to become septic.

Huving thus disisissed the probable true pathology of the asate furms of mammary abscoss a word may be said as to the position and effects of purulent collections within the gland. In nearly all our text-books the division is made into the supra-mammary, the intra-mammary, and the submammary ahscess. As regirds the first variety, the pus Fims immediately beneath the skin of the areola, and in a con-irerable number of cases is doubtless due to suppuration in some of the sebaceous structures (glands of Montgomery) whis exist in that position. As regards the sub-mammaiy abscess I may at once state my belief that abscess really beneath the gland is far more rare than is generally believed. I may here state that I have never seen a case of true sub-mammary abscess except as a consequence of caries of the ribs or empyema. I have, indeed, been shown examples where the breast has been pushed forwards as though by pus behind it, but in all of them I have found in operation that the purulent collec. tion has been in the deeper part of the mammary gland itself and not entirely beseath it. In short, it may be said that the majirity of mammary abscesses of gravity or signific tnce are found in the sub-tance of the breast itself. Great havoe is wrougbt by untreated suppuration in the breast. The abscess burrows extensively and in a branching and irregular manner so that numerous pockets or recesses are formed and multiple "pointings" and sinuses may only too readily ensue. A fatal resulo from septicæmia very rarely ocsurs, but in severe cases the patient may be invalided for many months and suffer very severely. Sinuses may be so persistent, discharges so profuse, and destruction of the mammary gland so great that amputation has even been thought needful, as in the following case.

A maried woman aged forty-four years was in University Culi ge Hospital in 1881. She had had five healthy chilitren and then six miscarriages. Beyond this there was no suspicion of syphilis and no symptoms or history of tuberculosis. She har never sur:kler with the left breast which had been inflamed and tender for about eight weeks. The upper and iuner part of the left mamma from the third cartilage to the xiphoid was firm, tender, and lobulated, the skin being red and adherent over $10 \mathrm{w}$ rounded prominences. Three sinuses near the nipple were discharging thin yellow pus from a superficial abscess. The liver and spleen were enlarged, smooth, and not tender. Menstruation was normal. The evening temperature was raised. The gland was described as riddled with sinuses and was amputated under antiseptic conditions, and the wound speedily healed. The gland was indurated, traversed by sinuses with granulating walls, leading to a cavity beneath the breast. The ducts were full of soft caseating material. ${ }^{21}$

In the breast it especially happens that abscesses are prone to become constricted in one part, where the pus has burrowed through a fascia or intra-mammary septum. The abscess then assumes a shape which may well be likened to an hour-glass. This most important variety of mammary abscess is too little noticed in modern times, but was long ago well described by Velpeau under the term "abscès en bouton de chemise."22 I have seen several examples of this condition. The abscess show itself as a subcutanecus swelling, and if the usual practice is adopted of making an incision radiating from the nipple the discharge will coutinue indefiritely: the true explanation being due to the fact that the main bulk of the pus is found deep in the substance of the gland communicating with the collection found under the skin of the areola by a narrow and sometimes sinuous channel of considerable length. I shall refer to this varitty of abscess again when speaking of the subject of treatment, and meanwhile I may only point out that the likeness of the shape of the abscess to a shirt button as stated by the French writer is peculiarly appropriate.

I propose next, as briefly as possible, to pass in review the pathological causation of the more chronic varieties of mammary abscess which, though comparatively infrequent, are not less important than the acute on account of the numerous diagnostic difficulties and errors to which they give rise. And first it will be convenient to consider the influence of tubercle in producing abscess of the breast. Sir Astley Cooper noticed long ago the existence of "scrof ulous tumours "in the breasts of single women; the skin becomes sof tened over them and finally gives way with a discharge of thin watery or curdy pus. The axillary glands are prone to share in the mischief, becoming enlarged and slowly suppurating. Dr. Charles A. Power ${ }^{\approx 3}$ reports a case operated upon by Bull in 1836. This writer finds anthertic lecorls of 35 cases. Of these, 34 were in females and 1 in a male. Of the 34 women, 22 were married and 5 were single. In 8 these conditions were not mentioned; 21 of the 22 women had borne children and 6 had suppurative inflammation of the breast, while 3 had had influmation not going on to suppuration. In 18 the jight breast was affected; in 14 the lefo breast, and in 1 both glanis. Trie youngest patient was seventeen years and the olye th fifty-two vears. Excellent examples of this affection are related by Hehb and Shattock in the Transactions of the Pathnlogical Society for 1883. and an extensive biblingraphical liat is given by Shattock in THE LANCET of June $8 \mathrm{~h}, 1889$, which cumprises most, if not all, of what has been written regarding the subject ap to that date. Payne ${ }^{21}$ has related a remarkable examivle of tuberculous abscess near the nipple of a child who sursequently died from general tubeiculosis. The importart question of the transmission of tubercle by a motber to her child from the milk was discussed in this case. Most opinions were in favour of the possibility of this, though ore observer pointed out that he believed Colles' law held gond in tuberculosis as well as in syphilis. Personaily, I have met with six cases of tuberculous abscess of the mamma, but I will only quote ore of them, which will serve as an example of the others. In June, 1893 I saw at the Hospital for Women and Children in the Waterloo-bridge-road a pale, emaciated, worn woman aged forty-three years who had the scars of old glard di iease in her neck and who had lost two children from phthisis. She herself had twice experienced atticks of hemoptysis and had suffered with the left breast for about twelve months, "a lump" having broken and discharged. On the axillary aspect of the left mamma was a ragged cavity with livid undermined edges. The axllary glands were enlarged and one of them distinctly fluctuated. Close to the abscess cavity the breast was much indurated ard

21 University College Hospital Reports, 1861.

22 Velpeau : Treatise on Diseases of the Breast, p. 75. 23 Annals of Surgers, vol $x \times 1894$.

24 Meeting of the Pathological Society, May 25th, 1889. 
thicker ed. The dis sharge was thin and watery, but no tubercle bacilli were found therein. The axillary abscesses were opened and the ulcer scraped and dressed with iodoform. It never soundly healed and the woman would not consent to any more radical measures being adopted. As an instance of this affection occurring in a man I may quote the following. The prtient, aged thirty-one years, was in the Westminster Hospital under Mr. Macnamara on Sept. 20th, 1893. Six months befure admission he had noticed a lump in the left breast, which was painless. No history of syphilis was obtainable, but the man stated he was struck with a bar on the past a year previou.]y. The tumour is described as forming an indolent lump, movable and not affecting the skin; the nipple was normal. There was slight iglandular enlargement in the axilla. A considerable portion of the breast was removed with the caseous mass, but the affected glands were apparently left.

It would serve little useful purpose to quote numbers of those cases, for their pathology and clinical significance are very similar to tuberculous maladies occurring elsewhere. The abscess may be singular or multiple, and the surrounding breast substance bealthy or more commonly riddled with small cavities containing caseating material. Thus the French writers will divide these cases into disseminated isolated tubercle, confluent tubercle, and "cold" abscess. ${ }^{25}$ Practically speaking, tubercle of the breast will seldom or never come before the surgeon until its grosser symptoms are manifest. It is especially important to note that the bacillus is not always found in the discharge and the presence of caseating material on the walls of the abscess and around it is the principal distinguishing sign to the naked eye.

The symptoms of these important abscesses may thus be summarled. They are indolent in progress, forming chronic-and of ten-hard lumps in the breast of those who commonly exhibit signs of the tuberculous diathesis or have marked hereditary proclivities towards tuberculous disease; the skin is commonly slightly reddened over the centre of the swelling; and finally, when fluctuation occurs and thin, watery pus is evacuated, an unhealthy ulcer with livid, overhanging edges and feeble granulations is generally left. The axillary glands are very of ten affected, and this, together with the bardness of the swelling in its earlier stages, has probably led to the diagnosis and treatment for cancer being adopted more frequently than surgeons are apt to allow. While exceptionally occurring in very young or in old individuals it may with truth be said that the majority of chronic abscesses of the mammary gland are not tuberculous and their pathology and causation are matters of the highest interest and cinical importance. Typical cases of this nature are found in women forty years of age and upwards in whom lactation has long been in abeyance and in whose cases apparently no known cause can be adduced. I have already stated my belief and quoted a case in point that the true explanation of many of these obscure cases is the entrance of organisms through some slight breach of surface on the nipple or at its base. Another patbological point of great interest and importance as regards the pathology of these abscesses is the frequency with which one finds a history of antecedent abscess or inflammation in the breast, it may be many years before. So fre quently do I find this, that one cannot doubt but that many cbronic abscesses of the mammary gland are what were well termed by Paget "residual abscesses." 26 We have at present no certain means of knowing how long a time organisms may lie latent within the tissues, to be started into activity by some form of stimulation, and the whole question of the latency of organisms of disease is an untrodden ground rich with interest and importance. Some of the several instances I have seen of chronic abscess arising in a mammary gland, the seat of old-standing suppurative mischief, may now be quoted.

A married woman aged forty-two years was admitted into St. Gecrge's Hospital on Aug. 20th, 1888. She had been married twenty-three ye ars and had borne ten children. Her last pregnancy was four years ago. Sixteen years before admission she had an abscess of the right breast, which had burst. Since then she had never been able to suckle with that breast. Six weeks ago, with no apparent cause, the right breast became painful and gradually

25 Jamain et Terrier: Pathologie Chirurgicale, tome ir., deuxième tascicu'e, p. $7(2$. ${ }^{25}$ Clinical Lectures and Essays, p. 309. swelled, and finally another abscess burst in the exact site of the former one. There was a sinus in the breast leading into indurated tissue. These conditions were cured by ordinary treatment. A married woman aged forty years saw me at the Waterloo-bridge-road Hospital for Women on Nov. 25th, 1874. Her right breast had become painful and swollen without any known cause for eight weeks. Sbe had had twelve children and four years ago had two abscesses in the right breast. The scars of the sinuses resulting were still to be seen. Her last child was born four years ago. On examination the right breast was irregularly swollen and just internal to a deeply retracted nipple were two rounded, led, fluctuating swellings, obviously abscesses. These were opened, scraped, and the tube brought out below as will be hereafter explained. The pus contained the staphyloccccus aureus in abundance. It is only right to point out that although in a number of instances of chronic abscesses of the breast there is a history of past suppurative affections, yet cases are met with where no such explanation, or, indeed, any rational explanation, is possible. These abscesses may occur in any part of the mammary gland but are commonly deeply seated. They are surrounded by much dense indurated tissue and the contents are thick and inspissated. From time to time surgeons have drawn attention to the extreme similarity between these affections and scirrhous cancer, and even with our modern knowledge diagnostic mistakes between chronic abscess and cancer more frequently occur than surgeons are willing to allow.

The symptoms of acute mammary abscess are so well known. that it would be idle for me to attempt to enlarge upon them. Yet cases are related where acute inflamed cancer exactly simulates them. Mr. Howard Marsh, in vol. xxiii. of the St. Bartholomew's Hospital Reports, bas recorded an admirable example of this condition. A most remarkabie case of inflamed carcinoma simulating abscess was under the care of my colleague (Mr. Dent) at st. George's Hospital in March of this year. The patient was a pale, emaciated, wanlooking, single woman aged thirty-seven years, and her right mamma had been getting swollen and painful for three months. The symptoms of abscess were all exemplified in redness, swelling, heat, and pain, with elesticity and fluctuation, but the pain was "shooting," not "throbbing," in nature and the skin over the swelling showed the appearance of peau d'orange. An incision revealed a breaking-down growth with a cavity in its centre full of blood and serum. Microscopically the growth after removal proved to be scirrhus. The diagnostic importance of the symptom of peau d'orange was thus shown to be very great. It is otherwise with the chronic variety of mammary abscess. The depth at which these abscesses are situated, the induration of the tissues round them, the frequent coexistence of a retracted nipple, and chronically enlarged axillary glands make the diagnosis from scirrhus impossible without exploratory incision. Nay, even this may mislead. On Aug. 28th, 1894,' I saw a spare, healthy. looking woman aged twenty-seven years, a patient of MIr. Hugh Webb of Parson's-green, who was suffering from a tumour of the left breast. She had never been pregnant. She had noticed the occurrence and gradual enlargement of the tumour for about four months. The nipple was deeply retracted and beneath it, incorporated with the breast tissue, was a hard mass, feeling in all respects like a mass of cancer. The axillary glands were not affected. The family history was good. There had never been discharge from the nipple. An exploratory incision was made irto the mass and some pus welled up, but the tissue was so dense and bore so exact a resemblance to cancer that it was thought wise to remove the whole breast. The abscess was the size of a small walnut, situated deeply beneath the nipple, and surrounded by hard indurated tissue to the extent of half an inch. Dr. Rolleston kindly examined this tissue with the microscope, and I append bis report: "Groups of atrophied and compressed mammary tubes enclosed in well-formed old fibrous tissue ...... sections of the wall of the abscess shewed well-formed fibrous tissue with an irregular lining of small cells, among which there are some traces of hæmorrhage." It is questionable in cases like this whether removal of the breast is or is not the right course to pursue, and upon this most important point opinions may well be divided. The records of every hospital. if carefully perused, will afford instances of confusion between chronic abscess and carcinoma of the mamma, and will exemplify the trath that the precaution of adopting 
an exploratory incision will alone discriminate between these affections. A series of chronic mammary abscesses simalating cancer are quoted by Reclus, ${ }^{2 \pi}$ and the same subject is dealt with at length by Castex ${ }^{2 \times}$

I have intentionally somewhat hurried over the subject of the symptoms of mammary abscess, for they are tolerably well known, and I am anxious to dwell upon some points in connexion with the treatment of the disease which I believe to be of the highest importance. In the first place acute mammary abscess should be a preventable disorder if the medical attendant is careful as to the cleansing of the nipple and of the mouth of the child, and is aware of the importance of attention to the proper care of the nipples previously to marriage. In certain cases of mal-development of the nipples fissures or ulcer will arise and in such abscess may occur even with the best care. I propose to speak of the purely operative treatment of acute ab-cess of the breast, without ignoring the important accessories of weaning the child, supporting the breast, the administ,ation of various drugs, or expression of the milk by massage and the exhausting pump. The prevention of mammary absce-s by expression of milk, and the use of an exhausting $b$ ittle to the mipple, is favourably spoken of by Spencer and Beale. ${ }^{29}$ The latter also adrocates the treatment of mammary abscess by opening with a trocar and cannula, and applying the exhausting bottle to the aperture. While I am ready to admit that this treatment might be applicable to small superficial abscesses, I shocld hesitate to apply it to deeply-seated ooliections of pus with loculi in the substance of the gland. I feel quite sure that the treatment of acute mammary abscess by the method of establishing a free opening anteriorly radiating from the nipple is essentially wrong. It leaves a scar on the front of the brea-t and, what is of greater importance, it opens the purulent collection in a position the least suitable for drainage. As a consequence many of these cases need several operations antil drainagetubes are seen projecting through various openings and very unsightly scarring results with subsequer,t deformity and grave interference with the functions of the gland. In a considerable majority of the cases I have been able to collect from the records of St. George's and other bospitals seraral operations under anæsthetics were often needful. This clearly means ineffici $i$ nt drainage. I will now describe the method of treatment I have !ound efficacious in several cases, trusting that those who have extensive prastice among parturient women will give it their careful consideration. So soon as elasticity and deep fluctuation are evident an incision is made radiating from the nipple just large enough to admit the index-finger of the operator and this is deepened until pus flows. The finger is now passed into the cavity, and in the vast majority of cases it will be found that the end of the digit may be brought fairly near the surface in a dependent position, and this is generally at the thoracic mammary junction. In this situation it may especially be noted that scars are hidden from view. Sometimes the finger passes towards the axillauy margin, and occasionally the cavity is so large that a stout bent probe must be used to indicate the deepest part of the abscess. In this situation, the gland being well raised by an assistant, a free opening is to be made, large enough to well evacuate the pus, and the finger being now introduced through this the inferior opening, the operator will be surprised to find that the pus bas burrowed about, and is contained in loculi bounded by fibrous septa. It is especially noteworthy that in many cases quite a narrow channel towards the nipple connects the deep abscess with the more superficial collection of pus opened anteriorlv, and it will then be cleally understood how inefficient is drainage in the practice of those who are content with a small incision anteriorly in these cases. The remainder of the treatment is obrious; the cavity is well flu-bed out with whatever agent the operator fancies, and a full-sized tube is introduced from below. The opening made near the nipple is closed with fine horse-hair and painted with collodion. It readily unites with only a faint scar. ard the free drainage prevents the possibility of the re-collection of pus and a necessity for further operation. The tube, a large one, can be left in the cavity as long as needful and is slowly shortened and withdrawn. It may seem superfluous to mention that the drainage-tube should be secured with a

27 Cliniques Chirurgicales, 1888 , page 417

21 Revue de Ĉhirurgie, 1887. piece of silk, but the fact of the tube havmg entered an abscess cavity and having been there retained or only removed by a troublesome operation must rot be lost sight of. This accident may rearlily happen unless special care be taken. The unsightly scar is completely lidden by the position and volume of the gland above.

The treatment of chronic abscess of the breast is a matter of greater difficulty and mu:t ever rai-e differences of opirion. The importance of exploratory inclsion bas already been raised, and I would here make a statement which may seem exaggerated, but which experience and a perusal of the literature of the subject permit me to positively advance. There is no symptom of scirrbous cancer of the breast which may not be simulated by a chronic abscess enclosed in a dense mass of inflammatory material, and unless $\epsilon x-$ ploratory measures are made as a matter of course grave errors of treatment will occasionally arise. The diagnosis of chronic abscess being establisbed one of the first thoughts which should arise is as to the presence or absence cf tabercle. The thin and watery nature of the pus with the pre-ence of caseating material in the walls of the abscess is one of the best vaked.cyed terts that can be applied. Many writers seem to be in favour of removing the entire breast in cases which appear to be of a tuberculous nature. With reference to this very important point in operative surgery much will depend up' $n$ the ex'ent of the disease. In disseminated tubercle, where several abscesses or masses of caseating material are disseminated in the breast, removal of the entire organ, with possibly the axillary glands also, is undoubtedly the right treatment to adopt. "With regard to non-tuberculous chronic abscesses there is again no absolute rule. When the abscess is surromnded by tolerably healthy mammary tissue and bas moderately thick parietes the free use of the spoon. with scraping and flushirg and drainage in a dependent po-ition in th $\mathbf{e}$ thoracic mammary furrow, will give good results. But if the ahscess, as in one of the cases I have related, is enclosed in a dense mass of inflammatcry tissue infil rating the greater part of the breast, and espreially if the patient be at the age when scirrhus is frequent, removal of the entire organ $i=$, in $m y$ belief. the wiser course to pursue. Regarding this question there is much difference uf opiaion. It is always most difficult in practice to determine at the moment what is best for the patient, and the operative treatment of chronic abscess of the breast is emirently one for consideration and discussion. I can only assert my belitf that breasts are removed too frequently for the:e aftections, and that free drainage in a dependent position with erasi $n$ and flushing will negative the necessity for the more serious operation in the vast majority of cases we meet with in practice. Cavendish-place, $W$.

\section{ON THE FORMATION AND STRUCTURE OF DENTAL ENAMEL.?}

\section{BY J. L E O N W I L L I A M S, D.D.S. B.LLTIMORE,} L.D.S.R C.S.I.

ALMOST every anatomist or histologist of note since the time of Juhn Hunter has made some contribution to the subject of this paper. In going over the literature of the theme one is struck by the wide divergence of opinion expressed-a divergence which is as nuarked and emphatic to-day as it was forty or fifty years ago. Broddly speaking, all who have written on the subject may be separated into two groups or schuols: those who have taugut that the furmation of enamel is effe ted by direct cell calcification and those who have claimed that the tissue is produced by a secreti,n-by the calcifiuticn of a cell-product. Between 1850 and 1860 Profe-sor Carpenter was maintrining the furmer pusition, and during the same time the late Professor Huxley wrote several pauers antagonising this view, and claiming that enamel couid nut be produced by any converion of a cellular stıucture. Curiously enough, his main contertion was correct, although fourded upon mistaken premisses. In 1848 the late Sir John Tomes delivered a course of lectures in which he taught that enamelformation is the result of the calcification of the enamelforming cells. His son, Mr. Charles Tomes, in the last 